\title{
Optimal Decisions and Risk Assessment in Sustainable Supply Chains
}

\author{
Sadok Turki *, Christophe Sauvey, Sofiene Dellagi and Nidhal Rezg
}

Citation: Turki, S.; Sauvey, C.; Dellagi, S.; Rezg, N. Optimal Decisions and Risk Assessment in Sustainable Supply Chains. Sustainability 2021, 13, 12198. https://doi.org/10.3390/ su132112198

Received: 28 October 2021 Accepted: 30 October 2021 Published: 5 November 2021

Publisher's Note: MDPI stays neutral with regard to jurisdictional claims in published maps and institutional affiliations.

Copyright: (c) 2021 by the authors. Licensee MDPI, Basel, Switzerland. This article is an open access article distributed under the terms and conditions of the Creative Commons Attribution (CC BY) license (https:/ / creativecommons.org/licenses/by/ $4.0 /)$.
Laboratoire de Génie Informatique, de Production et de Maintenance (LGIPM), Université de Lorraine, UFR MIM, 3 Rue Augustin Fresnel, F-57070 Metz, France; christophe.sauvey@univ-lorraine.fr (C.S.); sofiene.dellagi@univ-lorraine.fr (S.D.); nidhal.rezg@univ-lorraine.fr (N.R.)

* Correspondence: sadok.turki@univ-lorraine.fr

\section{Contents of the Special Issue}

Due to environmental preoccupations and potential economic benefits, production firms are devoted to developing and improving the decisions within sustainable supply chains (SSC). Consequently, currently, many manufacturing managers are working hard to find optimal decisions and coordination in SSC, such as manufacturing and remanufacturing planning, acquisition quantities of worn products, adaptation of new maintenance strategies and technics, optimal manufacturing design, reconfiguration, etc. However, these decisions may account for economic or ecologic risks, e.g., profit losses or excessive carbon emissions, which have prompted many researchers to develop different models that estimate and analyze risk in supply chains. Thus, to bridge this gap in the literature, this proposed thematic issue aims to contribute to the existing literature by investigating new decisions in SSC and risk analysis under undesirable events.

Concerning these decisions in SSC, three papers of this Special Issue (contribution numbers 7, 10, and 13) dealt with optimal decisions on production. Byungsoo Na, Min Kyu Sim, and Won Ju Lee (contribution number 7) considered a supply chain in the automotive industry in which a single supplier adopts returnable packages for delivery operations to a single recipient. The authors provided simulated experiments under the uncertainty of demand and reverse logistics delays to determine the optimal quantity of returnable packages. Sensitivity analysis was then realized by varying the assumptions on operation duration, demand, and lead time variabilities. The obtained results indicate that a greater initial purchase of returnable packages is desirable for longer operation duration, higher demand, and lead time variabilities. Amir Baklouti, Lahcen Mifdal, Sofiene Dellagi, and Anis Chelbi (contribution number 10) proposed an optimal preventive maintenance strategy for a solar photovoltaic system composed of solar panels functioning as a series system. The authors proposed an analytical model to determine simultaneously the optimal preventive maintenance period and the optimal number of solar panels to be replaced at each preventive maintenance. The economic relevance of the proposed preventive maintenance strategy is shown through estimation of the economic gain when comparing the situations with and without preventive maintenance. In contribution 13, Gaoke Wu, Bo Feng, and Libin Guo provided a trade credit strategy model with the supplier for a two-echelon supply chain composed of a well-funded supplier and a capital-constrained retailer with risk-averse preference. The authors derived the model solution and provided optimal decisions to all petitioners. The obtained results show that the optimum order quantity under the conditional value-at-risk criterion declines the confidence level, and the wholesale price of the supplier increases the confidence level. It is shown that when the retailer requires fewer orders, the supplier will correspondingly increase the wholesale price to maximize their profit.

Another subject is addressed in this Special Issue by considering carbon emissions. Xing Yin, Xiaolin Chen, Xiaolin Xu, and Lianmin Zhang (contribution number 8) investigated the carbon tax policy from the perspective of an SSC, which consisted of the upstream 
government and the downstream manufacturing company. The government decides on the tax regulation to maximize the social welfare, while the company decides on the greenness level of the product, which affects consumer choice behavior and their own demand. It was found that the government should adopt a tax regulation if consumers are very sensitive to greenness, the cost of greening is high, or the negative impact due to carbon emission is large, or otherwise subsidize the firm. Chang Su, Xiaojing Liu, and Wenyi Du (contribution number 9) also considered the consumers' green preference in the case of different government subsidies. The authors discussed the impact of a government subsidy coefficient on the optimal decision of a green supply chain. They showed that, whether the government subsidizes the manufacturers or the consumers, the wholesale price offered by the manufacturer is directly proportional to the subsidy coefficient under the two power structures. In addition, when the government subsidizes the manufacturer, the carbon emission level and the retail price are inversely proportional to the subsidy coefficient under the manufacturer leader; the carbon emission level and the retail price are all directly proportional to the subsidy coefficient under the retailer leader. In the third option, when the government subsidizes the consumers, the carbon emission level and the retail price are directly proportional to the subsidy coefficient under the two power structures. The carbon emissions policy is also addressed in the air traffic issue by Mohamed Ali Kammoun, Sadok Turki, and Nidhal Rezg (contribution number 11) that have dealt with the flight rescheduling problem, taking into account the environmental requirement subject to the air capacity limitation due to weather changing. The authors proposed a new strategy to minimize the disruption effects on planned flights, which adopted ground delay, longer route change, flight cancellation, as well as speed adjustment to arrive at a scheduled time. The impacts of a carbon tax and the cost of arrival delay on the flights' carbon emissions were studied and analyzed.

Risks are a very important part of the business environment, and if they are well managed, they can provide a significant advance with regard to concurrent companies, as well in terms of competitiveness regarding sustainability. Oláh, Virglerova, Popp, Kliestikova, and Kovács proposed to create a risk profile for small and medium-sized enterprises, dealing with legal, security, personnel, and operational risks. Four countries were compared with Serbia (Czech Republic, Slovakia, Poland, and Hungary) with regard to the risk levels assessed (contribution number 5). In addition, fair investment plans were also investigated to enhance supply chain visibility through the prism of cooperative games (contribution number 1). The framework proposed by Kim and Shin considers the relationship among participants, as well as the impact from enhanced visibility, and it may be possible to make fair and rational decisions for all participants based on quantitative metrics such as the benefit-to-cost ratio. In their paper, they proposed a novel method based on the game-theoretic approach, in which enhanced visibility prevents a certain participant from taking most of the benefit. They set the basis to establish long-term SSC visibility by distributing profit fairly to all participants in the supply chain.

Another point treated by the authors in this special issue deals with coordination of the supply chain actors and with return loops issues. Return strategies and online product customization in a dual-channel supply chain were investigated by Zhang, Li, Huang, and Liu. In their paper, they identified that a manufacturer prefers offering a money-back guarantee as long as the net salvage value of the returned product is positive in a channel and showed that the demand and profit of the manufacturer increase to a certain extent when opening an online customization channel (contribution number 2). In their approach, $\mathrm{Xu}, \mathrm{Liu}$, and $\mathrm{Xu}$ examined the recycling channel options for a manufacturer applying ecodesign under government environmental regulations. They found that for a manufacturer, the recycling channel choice depends on the recycling costs of the manufacturer and the retailer. They determined a threshold to decide whether the manufacturer alone must recycle the waste products or transfer the recycling task to the retailer (contribution 12).

The coordination of the actors in the supply chain is a key issue. In their paper, $\mathrm{Su}$, $\mathrm{Li}$, Zeng, Yang, and Zhang compared and analyzed the impact of centralized and decen- 
tralized decision-making on the returns and pricing strategies of each participant in a green closed-loop supply chain. They proposed an optimized cooperative mechanism decision model, considering a cost profit-sharing contract (contribution number 6). Meanwhile, Pérez-Mesa, Piedra-Muñoz, García-Barranco, and Giagnocavo analyzed the new supply chain management strategies of the largest retail distribution chains in Europe within the context of differing sustainability concepts and approaches. They carried out an analysis of the strategic plans of such retailers, as well as recent developments in the sector. They proposed strategic approximation and collaboration to bridge the gap between the varying sustainability demands in the supplier-retail relationship within perishable supply chains (contribution number 3 ). In the same context and aim of closed-loop supply chain coordination, $\mathrm{Zhu}, \mathrm{Yu}$, and Li proposed to design an effective warranty strategy through the warranty period decision and coordination in the supply chain, considering both remanufacturing issues and customer behavior. They discussed the optimal warranty decision-making for new and remanufactured products under centralized and decentralized decision-making models. They also showed the impact of the closed-loop supply chain system with warranty services and the design of contract coordination (contribution number 4).

Funding: This research received no external funding.

Conflicts of Interest: The authors declare no conflict of interest.

\section{List of Contributions:}

1. Kim, C.; Shin, K. Developing Fair Investment Plans to Enhance Supply Chain Visibility Using Cooperative Games. Sustainability 2019, 11, 3209.

2. Zhang, R.; Li, J.; Huang, Z.; Liu, B. Return strategies and online product customization in a dual-channel supply chain. Sustainability 2019, 11, 3482.

3. Pérez-Mesa, J.C.; Piedra-Muñoz, L.; García-Barranco, M.C.; Giagnocavo, C. Response of fresh food suppliers to sustainable supply chain management of large European retailers. Sustainability 2019, 11, 3885.

4. Zhu, X.; Yu, L.; Li, W. Warranty period decision and coordination in closed-loop supply chains considering remanufacturing and consumer behavior. Sustainability 2019, 11, 4237.

5. Oláh, J.; Virglerova, Z.; Popp, J.; Kliestikova, J.; Kovács, S. The assessment of non-financial risk sources of SMES in the V4 countries and Serbia. Sustainability 2019, 11, 4806.

6. $\mathrm{Su}$, J; Li, C.; Zeng, Q.; Yang, J.; Zhang, J. A green closed-loop supply chain coordination mechanism based on third-party recycling. Sustainability 2019, 11, 5335.

7. Na, B.; Sim, M.K.; Lee, W.J. An optimal purchase decision of reusable packaging in the automotive industry. Sustainability 2019, 11, 6579.

8. Yin, X.; Chen, X.; Xu, X.; Zhang, L. Tax or subsidy? Optimal carbon emission policy: A supply chain perspective. Sustainability 2020, 12, 1548.

9. Su, C.; Liu, X.; Du, W. Green supply chain decisions considering consumers' low-carbon awareness under different government subsidies. Sustainability 2020, 12, 2281.

10. Baklouti, A.; Mifdal, L.; Dellagi, S.; Chelbi, A. An optimal preventive maintenance policy for a solar photovoltaic system. Sustainability 2020, 12, 4266.

11. Kammoun, M.A.; Turki, S.; Rezg, N. Optimization of Flight Rescheduling Problem under Carbon Tax. Sustainability 2020, 12, 5576.

12. Xu, S.; Liu, H.; Xu, G. Selection of Recycling Channels and Product Eco-Design with Take-Back Regulation. Sustainability 2021, 13, 8961.

13. Wu, G.; Feng, B.; Guo, L. Optimal Procurement Strategy for Supply Chain with Trade Credit and Backorder under CVaR Criterion. Sustainability 2021, 13, 10201. 